\title{
Managerial response to stockouts: the effect of remedies on consumer behavior
}

\author{
Ester Quirino Dias Sampaio ${ }^{\mathrm{a}}$, Mauro Sampaio ${ }^{\mathrm{b} *}$ \\ ${ }^{a}$ Centro Universitário da FEl, São Paulo, SP, Brasil

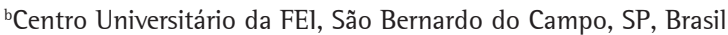 \\ *msampaio@fei.edu.br
}

\begin{abstract}
Stockouts remain a significant problem for retail firms. Estimates of stockout rates in the past fifty years consistently averaged approximately 8 percent. The consequences of stockouts transcend the retail store to include its supporting supply chain. In addition to the effect on the behavior of consumers, stockouts can impact the firm's replenishment policy, the level and location of inventories and the cost of emergency shipments required to replenish out-of-stock items. Although there is a substantive literature in logistics that measures the frequency of and the consumer response to stockouts, investigation of the effect of remedies on consumer response is sparse. To address this problem, the effectiveness of five remedies as tools to manage retail stockouts was investigated: apology, raincheck, home delivery, trade-up and discount. A remedy is an incentive to induce consumers to not leave a store in response to a stockout. In addition the influence of consumer characteristics (i.e., brand loyalty) and shopping situations (i.e., urgency of purchase) on the effect of each remedy on consumer behavior was examined. The results suggest that the remedies are usually effective. The most effective remedy is home delivery. The least effective remedy is a simple apology, which may actually increase the percentage of consumers leaving the store. The results also indicate that the urgency of the purchase and store loyalty have the most impact on remedy effectiveness. These results suggest that there are significant opportunities to use remedies as tools to manage the effect of stockouts on retail stores and their supporting supply chains.
\end{abstract}

Keywords

Stockout. Logistics. Design of experiments.

Stockouts are broadly recognized by researchers and practitioners as a significant problem for retail stores and their supporting supply chains. Estimates of stockout rates in retail stores have consistently averaged 8 percent (Vasconcellos \& Sampaio 2009; Corsten \& Gruen, 2004; Grocer, 1968). The stockout problem is important to the supply chain because stockout rates affect replenishment policies. Stockouts also affect the size and location of inventories because firms must maintain an appropriate level of inventory to manage the level stockouts. Such inventory must have an adequate size and be located within range for a reasonable lead time. Moreover, stockouts often require an emergency shipment as a response. Logistics managers are typically among those tasked with preventing and taking corrective measures in response to stockouts.

Retail stockouts have been studied from two major perspectives: measurement of stockout rates in stores and consumer response to stockouts (Berger, 2003; Zinn \& Liu, 2001). Regardless of the perspective, most studies suggest that managers deal with stockouts by taking action to reduce the number of stockouts as much as possible (Corsten \& Gruen, 2003; Berger, 2003).

In contrast, in this research It was investigated the effectiveness of remedies as an alternate approach to managing stockouts. A remedy is an incentive to induce consumers to not leave a store in response to a stockout. Although there are a few papers that explore the potential value of remedies to manage stockouts, this idea is still largely underesearched (Anderson et al., 2006; Bhargava et al., 2006).

While taking action to reduce the number of stockouts is clearly an important component of stockout management (Aguiar \& Sampaio, 2014), it is likely insufficient to solve the problem. There are 
two major reasons for this. First, despite all efforts so far, stockout rates have remained high over a prolonged period of time, as shown in Figure 1. The rates reported from Peckham (1963) to Berger (2003) are reasonably similar. Second, the stockout problem is becoming more difficult to manage due to the continued trends of product proliferation, scrambled merchandising and shorter product life cycles. Stockout rates will never be zero.

Consequently, stockouts should be managed with a combination of efforts to (1) reduce the number of stockout instances and (2) offer remedies to manage the consumer's response whenever the stockout is unavoidable or is too expensive to eliminate. While the literature is rich in methods to reduce the rate of stockouts, it is lacking in the issue of remedies.

Accordingly, to investigate the effectiveness of remedies as tools to manage consumer response to stockouts, it was conducted an experiment to explore the effect of five different remedies: apology, raincheck, home delivery, trade-up and discount. While the purpose of offering any remedy is to induce consumers not to leave the store in response to a stockout, each remedy can have a distinct effect on consumer behavior. For example, a raincheck induces the consumer to delay the purchase, while a trade-up or a discount induces the consumer to substitute the sought item. In this research, it was focus on the effectiveness of each remedy in inducing the consumer not to leave the store in response to the stockout. The product used in the experiment was TABLET.

In addition to the consumer's general response, it was examined how the consumer's characteristics and the shopping situation influence the effectiveness of each remedy in persuading consumers not to leave the store in response to a stockout. The four consumer characteristics considered were: brand loyalty, store loyalty, perceived store price and perceived product risk. The shopping situations examined were urgency to make the purchase, pre-visit agenda (planned vs. impulse buying) and surprise with the stockout.

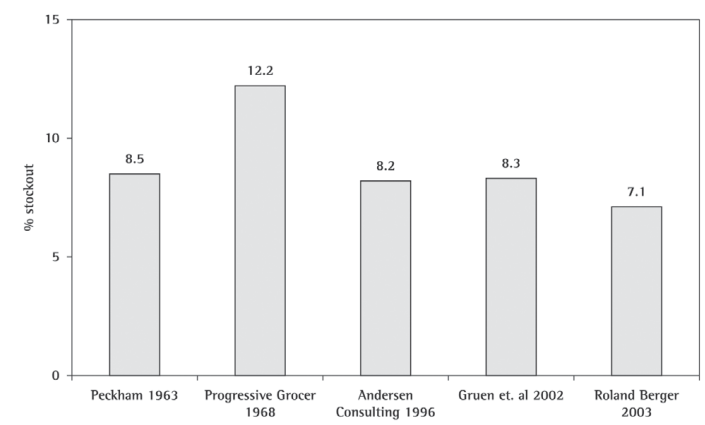

Figure 1. Percent stockout levels in previous studies.
Our results suggest that remedies work. While apology is an exception, all other remedies considered in the research are effective in inducing consumers not to leave the store in response to a stockout. For instance, in cases where there is no urgency in the purchase, an offer to deliver the out-of-stock item to the consumer's home was accepted by eight out of nine participants, who subsequently changed their intention to leave the store in response to the stockout. Our results also suggest that a simple apology can be counterproductive as it actually slightly increased the number of participants leaving the store in response to a stockout.

Understanding the effect of remedies on consumer response to stockouts is central to the retail supply chain. If remedies affect consumer response to stockouts, they consequently also affect the cost of a stockout. The cost of a stockout is in turn a key input to determine customer service levels and the corresponding inventory investment and transportation cost. This cost and service trade-off is the basis for deciding on issues such as store replenishment, the level and location of inventory as establishing criteria for making emergency shipments.

The remainder of this manuscript is divided into four sections. The first is a literature review. It is followed by a description of the methodology used, including the experiment design, variable selection, and data collection and analysis. The third section contains the results. The conclusions, limitations and managerial implications are in the fourth and last section.

\section{Literature review}

The retail stockouts literature began at least fifty years ago (Peckham, 1963). During this time frame, most publications focused on at least one of two broad issues. One was the measurement of stockout levels in retail stores and the other was the behavior of consumers in response to a stockout. Consumers may respond to the stockout by either substituting the item, delaying the purchase or leaving the store. This response set is known by the acronym SDL. The literature is summarized in Table 1, with special emphasis on SDL behavior because it is the basis for the framework lt was used to measure consumer behavior in this research. Some of the papers included in the table also report the percentage of respondents who "did not buy." This is a breakdown of the "Leave" behavior, whereby consumers either go to a competing store or quit the purchase altogether. Much of this literature is also reviewed in Fitzsimons (2000) and Zinn \& Liu (2001). 
Table 1. Retail stockouts literature related to sdl behavior.

\begin{tabular}{|c|c|c|c|}
\hline Author & Description & Method & SDL Behavior \\
\hline Peckham (1963) & $\begin{array}{l}\text { Measured stockout levels in grocery stores. Measured } \\
\text { also effects on brand loyalty and customer satisfaction }\end{array}$ & Exit Survey & $\begin{array}{l}\text { Did not Buy: } 6 \% \text { Leave : } 17 \% \\
\text { Delay : } 19 \% \\
\text { Substitute : } 58 \%\end{array}$ \\
\hline Grocer (1968) & $\begin{array}{l}\text { Documented stockout frequency in supermarkets and } \\
\text { measured SDL behavior }\end{array}$ & Exit Survey & $\begin{array}{l}\text { Did not Buy : } 0 \% \text { Leave : } 28 \% \\
\text { Delay : } 24 \% \\
\text { Substitute : } 48 \%\end{array}$ \\
\hline Walter \& Grabner (1975) & $\begin{array}{l}\text { Proposed a formal model that charted all possible } \\
\text { responses to stockouts. }\end{array}$ & Survey & $\begin{array}{l}\text { Did not Buy : } 0 \% \text { Leave : } 14 \% \\
\text { Delay : } 1 \% \\
\text { Substitute : } 83 \%\end{array}$ \\
\hline Schary \& Christopher (1979) & $\begin{array}{l}\text { Measured SDL behavior with respect to store image, } \\
\text { brand loyalty and demographic variables. }\end{array}$ & Exit Survey & $\begin{array}{l}\text { Did not Buy : } 0 \% \text { Leave : } 48 \% \\
\text { Delay : } 30 \% \\
\text { Substitute : } 22 \%\end{array}$ \\
\hline Emmelhainz et al. (1991) & $\begin{array}{l}\text { Measured SDL behavior after removing key products } \\
\text { from the shelf }\end{array}$ & Field Experiment & $\begin{array}{l}\text { Did not Buy : } 0 \% \text { Leave : } 39 \% \\
\text { Delay : } 21 \% \\
\text { Substitute : } 40 \%\end{array}$ \\
\hline $\begin{array}{l}\text { Coca-Cola Retailing Research } \\
\text { Councils (1996) }\end{array}$ & $\begin{array}{l}\text { Measured stockout rate and SDL behavior. Combined } \\
\text { store audits, scanner data, and personal interviews } \\
\text { with industry and consumers }\end{array}$ & Multiple & $\begin{array}{l}\text { Did not Buy : } 0 \% \text { Leave : } 31 \% \\
\text { Delay : } 15 \% \\
\text { Substitute : } 42 \%\end{array}$ \\
\hline Verbeke et al. (1998) & $\begin{array}{l}\text { SDL behavior by brand loyalty, store loyalty and } \\
\text { amount of purchase }\end{array}$ & Field Experiment & $\begin{array}{l}\text { Did not Buy : } 0 \% \text { Leave : } 24 \% \\
\text { Delay : } 21 \% \\
\text { Substitute : } 55 \%\end{array}$ \\
\hline Campo et al. (2000) & $\begin{array}{l}\text { Examined product characteristics, consumer } \\
\text { characteristics and situation characteristics as } \\
\text { correlates of SDL behavior. }\end{array}$ & Survey & $\begin{array}{l}\text { Did not Buy : } 0 \% \text { Leave : } 1 \% \\
\text { Delay : } 30 \% \\
\text { Substitute : } 66 \%\end{array}$ \\
\hline Zinn \& Liu (2001) & $\begin{array}{l}\text { Short-term SDL behavior in terms of consumer and } \\
\text { perceived store characteristics, as well as situational } \\
\text { and demographic variables }\end{array}$ & Survey & $\begin{array}{l}\text { Did not Buy : } 0 \% \text { Leave : } 23 \% \\
\text { Delay : } 15 \% \\
\text { Substitute : } 62 \%\end{array}$ \\
\hline Gruen et al. (2002) & $\begin{array}{l}\text { Measured stockout rates and SDL behavior in a } \\
\text { worldwide study of grocery stores }\end{array}$ & Secondary Data & $\begin{array}{l}\text { Did not Buy : } 6 \% \text { Leave : } 31 \% \\
\text { Delay : } 15 \% \\
\text { Substitute : } 45 \%\end{array}$ \\
\hline Berger (2003) & $\begin{array}{l}\text { Measured stockout rates and SDL behavior in a study } \\
\text { of European grocery stores }\end{array}$ & Survey & $\begin{array}{l}\text { Did not Buy : } 6 \% \text { Leave : } 27 \% \\
\text { Delay : } 15 \% \\
\text { Substitute : } 48 \%\end{array}$ \\
\hline Sloot et al. (2005) & $\begin{array}{l}\text { Measured SDL behavior related to brand equity and } \\
\text { hedonic products }\end{array}$ & Survey & $\begin{array}{l}\text { Did not Buy : } 0 \% \text { Leave : } 25 \% \\
\text { Delay : } 27 \% \\
\text { Substitute : } 48 \%\end{array}$ \\
\hline
\end{tabular}

It was reviewed more extensively the three papers that examine the effect of remedies on consumer response to stockouts. The Anderson et al. (2006) contribution focused on stockouts in a direct marketing environment, specifically medium and premium priced bedding and home accessories. One of the issues they examined was the effect of five different responses that a firm may adopt after a stockout in order to persuade consumers to wait until the product became available. The five responses were: (1) informing the customer that the items is out-of-stock, (2) informing the customer that the item is out-of-stock because of a problem with the supplier, (3) informing the customer that the item is out-of-stock because it is "extremely popular," (4) offering a \$5 discount on shipping charges if the customer agreed to backorder and (5) offering a $10 \%$ discount on the item if the customer agreed to backorder. Results showed that explaining that the out-of-stock item was very popular was more effective than financial compensation and that the latter could be unnecessarily expensive.

Bhargava et al. (2006) focused on a single remedy in an e-commerce environment. They examined how a policy of price discounts as compensation for stockouts may be integrated into inventory optimization problems. They suggest that the discount helps to recapture some of the lost demand due to the stockout. They further suggest that the resulting increase in demand reduces holding cost because the level of inventory is reduced. Ordering cost is also affected because the higher demand enables larger volume purchases.

In two online experiments, Kim \& Lennon (2011) research investigated the process by which consumers respond to online apparel stockouts and examined the effectiveness of managerial responses in mitigating the adverse impact of stockouts. Results of Experiment 1 demonstrated that negative emotions evoked by stockouts depressed perception of store image, lowered decision satisfaction, and reduced behavioral intent. In addition, the effect of negative emotion on behavioral intent was mediated by perception of store image and decision satisfaction. The results of Experiment 2 showed that financial compensation was most effective in mitigating the negative impact of out-of-stock occurrences on consumer responses. 
It was extend the literature in three different ways. First, it was researched a more comprehensive set of remedies. Second, it was looked at the effect of remedies in a traditional "brick-and-mortar" retail store format. Third, this paper go beyond the main effects of remedies by adding the influence of consumer characteristics and shopping situations on the effectiveness of each remedy. Understanding how remedies affect stockouts has significant implications for the retail supply chain. It affects the cost of stockouts and consequently store replenishment policy, inventory investment and spend in emergency shipments.

\section{Methodology}

Recall that the objective of the research is to understand the effect of five remedies on consumer response to stockouts and that it was also investigated the impact of four consumer characteristics and three shopping situations on the effectiveness of each remedy. In order to systematically manipulate the remedies and shopping situations, It was selected an experimental research approach. The consumer characteristics were captured in a questionnaire at the end of the experiment. The methodology section covers the (1) experiment design, (2) variable selection, and (3) data collection and analysis, respectively.

\subsection{Experiment design}

IT was adopted a before and after experiment design. Participants were first exposed to a stockout situation and then asked for their SDL response. A remedy was offered thereafter and participants were again asked for their SDL response. Each participant was asked to consider all five remedies, one at a time. The remedies appeared in random order. The effectiveness of each remedy was estimated by comparing the before and after SDL behaviors.

It is important to note that two of the remedies, trade-up and discount are quite similar. Discount is a direct monetary reward for the stockout, to be applied to the purchase of another TABLET. Trade-up is an upgrade to a more expensive TABLET for the price of the out-of-stock item. Despite the possibility that participants would not perceive differences between the two remedies, it was decided to maintain the same monetary value for both remedies in order to ensure that the remedies are being compared and not their difference in monetary value. The wording used for each of the 5 remedies is displayed in Table 2 .

During the experiment, participants were exposed to a MediaLab computer screen that described a hypothetical purchasing environment at a nationally known chain store. The chain sells electronic products and appliances. The product used in the experiment was TABLET. Each participant was exposed to six different TABLET models from three different national brands. In addition to measuring the effect of five remedies on consumer response to stockouts, it was examined the effect of consumer characteristics and shopping situations on the consumer's response.

The four consumer characteristics measured in the research, brand loyalty, store loyalty, perceived store price and perceived product risk, were captured in a short questionnaire administered at the end of the experiment. All questions were seven point likert scales anchored by "strongly agree" and "strongly disagree."

The scales used to measure consumer characteristics were based on the previous literature. The scales for brand loyalty and store loyalty were drawn from Campo et al. (2000) and the scale for perceived product risk from Erdem \& Swait (1998). It was also used the scale available in Zinn \& Liu (2001) to measure perception of store price.

The potential effect of the shopping situation on consumer response was operationalized through the use of eight scenarios. These scenarios were developed by systematically combining the three shopping situation variables included in this research: urgency of purchase (yes or no), pre-visit agenda (planned vs. impulse purchase) and surprise with the stockout (yes or no). For instance, one scenario creates a shopping situation whereby the purchase is urgent, planned and the consumer is not surprised by the stockout. Given that each variable has two

Table 2. Remedy Statements.

\begin{tabular}{ll}
\multicolumn{1}{c}{ Remedy } & Statement \\
\hline Apology & "1 am very sorry for the inconvenience, but there is nothing 1 can do to help you." \\
Raincheck & ar today price if you choose to return to (STORE NAME) in the future. \\
Home Delivery & "1 am very sorry for the inconvenience. Let me find the Tablet at another (STORE NAME) store and then send it to your \\
Trade-up & $\begin{array}{l}\text { "1 am very sorry for the inconvenience. Please accept an offer to trade the out-of-stock tablet for another one of a } \\
\text { siscount }\end{array}$
\end{tabular}


levels, the set of all possible combinations results in eight scenarios. Each participant was exposed to only one scenario.

These scenarios were introduced to participants in 2 separate steps. The four scenarios related to urgency of purchase and pre-visit agenda were introduced first. The scenarios related to surprise with the stockout were introduced after the participant became aware that the selected item was out-of-stock.

Sample scenarios are reproduced in the two paragraphs below. The first describes that the participant has a pre-visit agenda and the urgency of purchase is high. The second paragraph shows that the participant is surprised by the stockout.

Your TABLET fell and broke down. It happened in the evening before an important business trip where the TABLET will be needed. All your contact information, travel and meeting schedules, as well as hotel reservations are in the broken unit. While the information is saved, you can't access it until you get a new unit. You just drove to the local [Store Name] store to get a replacement. There are only a few hours left to buy a new TABLET.

This stockout really caught you off-guard. This is totally unexpected. The store should carry this item. You have seen it in their catalog and on their advertisements.

A schema of the experiment is in Figure 2. It describes the experiment in 7 steps.

- In step 1 participants were exposed to one of the first four scenarios and to the TABLET brands and models available for selection. In addition to a picture of each available item, there was a description of the item's features and price.

- In step 2 the participant selected one of the items.

- In step 3 the participant was informed that the selected item was out-of-stock and was subsequently exposed to one of the remaining 2 scenarios, namely whether or not the stockout was surprising to the participant.

- In step 4 the participant was asked for his/her SDL response to the stockout. This is the "before" measurement.
- Steps 5 and 6 are in a loop. In step 5 participants were first offered one of the 5 remedies to the stockout. The participant then indicated in step 6 whether or not the remedy would change his/her response to the stockout. This loop was continued until the participant went through the 5 remedies. To manage order bias, the remedies were offered in random order. This is the "after" measurement.

- Finally, in step 7, participants answered questions about their consumer characteristics.

\subsection{Variable selection}

Table 3 is based on the literature review. It lists significant variables included in previous consumer response to stockout studies. The variables selected for this research were included often in those studies. The most researched variable was brand loyalty, followed by store loyalty, urgency of use, pre-visit agenda, perceived store price and product risk. The variable surprise was included because it was found to be significant in a previous stockout study that included products similar to the ones used in this research (Zinn \& Liu, 2001).

\subsection{Data collection and analysis}

A sample of 552 undergraduate students of a major state university agreed to serve as participants in return for course extra credit. It was selected a student sample because demographic variables, especially age and education, have not been shown to be statistically significant in previous stockout research (Zinn \& Liu, 2001). In addition, undergraduate students are an actual market for TABLETs. Finally, student samples are successfully employed in consumer behavior experiments, including response to stockouts research (Petty \& Cacioppo, 1996; Fitzsimons, 2000; Deck \& Smith, 2013).

Prior to collecting data, it was conducted a pre-test with 80 participants. The goal of the pre-test was to check the realism and clarity of the scenarios. It was also checked for scenario recall and participant fatigue. The data from the pre-test was not included in the sample.

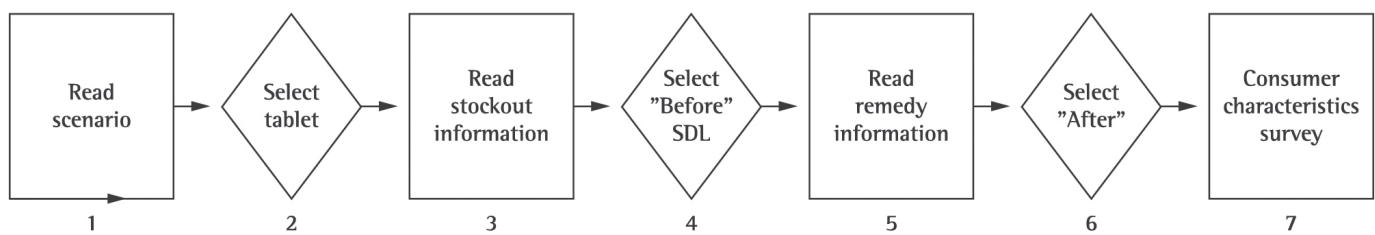

Figure 2. Steps in the experiment. 
Table 3. Significant variables included in previous studies.

\begin{tabular}{|c|c|c|c|c|}
\hline Variables & Paper & Substitute & Delay & Leave \\
\hline Brandy Loyalty & Zinn \& Liu (2001) & 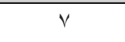 & & \\
\hline 1tem Loyalty & Campo et al. (2000) & $v$ & & \\
\hline Brand Preference & Verbeke et al. (1998) & v & & \\
\hline Brand Loyalty & Schary \& Christopher (1979) and & v & v & v \\
\hline Brand Loyalty & Sloot et al. (2005) & v & $v$ & v \\
\hline Repeat Brand Purchase & Emmelhainz et al. (1991) & v & & \\
\hline Brand Equity & Sloot et al. (2005) & v & & v \\
\hline Hedonic Level of a Product & Sloot et al. (2005) & v & & \\
\hline Stockpile Products & Sloot et al. (2005) & v & v & v \\
\hline Number of brands & Sloot et al. (2005) & v & & v \\
\hline Perception of Store Price & Zinn \& Liu (2001) & v & v & v \\
\hline Price Consciousness & Sloot et al. (2005) & & & v \\
\hline Store Loyalty & Verbeke et al. (1998) & & v & v \\
\hline Store Loyalty & Campo et al. (2000) & & & v \\
\hline Store Loyalty & Emmelhainz et al. (1991) & v & & \\
\hline Store Loyalty & Sloot et al. (2005) & v & & \\
\hline Part of the week & Sloot et al. (2005) & & v & \\
\hline Urgency in Purchase of item & Zinn \& Liu (2001) & v & v & \\
\hline Urgency of Need & Emmelhainz et al. (1991) & v & & \\
\hline General Time Constrain & Campo et al. (2000) & & & v \\
\hline Pré-visit agenda & Zinn \& Liu (2001) & & v & \\
\hline Intend Product Usage & Emmelhainz et al. (1991) & v & & \\
\hline Impulsive Purchase & Sloot et al. (2005) & & v & v \\
\hline Consumer is upset with stockout & Zinn \& Liu (2001) & v & & \\
\hline Surprise with stockout & Zinn \& Liu (2001) & & v & v \\
\hline Required purchase Quantity & Campo et al. (2000) & & v & v \\
\hline Amount of purchase & Verbeke et al. (1998) & & v & \\
\hline Perceived Product Risk & Emmelhainz et al. (1991) & v & & \\
\hline Availability of Alternatives & Campo et al. (2000) & & v & v \\
\hline Quality Conscientious & Sloot et al. (2005) & v & & \\
\hline
\end{tabular}

After completing the pre-test, participants were informally interviewed about their general impression of the experiment. During the interview, it was also checked for mundane realism, which refers to how typical or representative the procedures of the experiment are of everyday life (Brickman, 1981). It was asked participants to rate their perception of the of the purchase situation on a 7 point scale, where 7 meant "strongly agree" that the experiment is realistic. The average score was 5.5. This indicates that participants felt that the mundane realism of the experiment is adequate.

To gauge participant comprehension and recall of the scenarios in the experiment, it was conducted a manipulation check. It was introduced screens during the pre-test asking participants two questions about variables used to compose the scenarios in the experiment. The questions checked respondent understanding of the urgency of the purchase (yes or no) and awareness of the pre-visit agenda (browsing vs. specific item in mind). Ninety-five percent of the participants answered these questions correctly. Finally, It was determined that fatigue was not an issue as participants did not complain of fatigue during the informal interviews.

The sample data was analyzed in two separate steps. In the first step it was looked at the overall impact of each remedy on SDL behavior. The goal was to evaluate whether the remedy achieved its purpose of inducing change in SDL behavior in the direction desired by the retailer. In the second step it was conducted ANOVA analyses to measure the impact of the consumer characteristics and shopping situations on the effectiveness of each remedy. It was looked at main effects and two-way interactions.

Thus, for each remedy, it was checked the overall result, the main effects and the two-way interactions. More specifically, the overall result for a remedy corresponds to its impact on SDL behavior, particularly its effect on leave behavior. A main effect refers to the impact of an individual consumer characteristic or a shopping situation on the effectiveness of a particular remedy. Finally, an interaction refers to the joint impact of two consumer characteristics or shopping situations on the effectiveness of a particular remedy. 
It is important to note that the dependent variables considered for the overall result and the ANOVA are not the same. In the overall result this paper focuses on leave behavior because this is the behavior of greatest interest to the retailer. However, for the main and interaction effects a single dependent variable that focuses on all possible changes in SDL behavior was required. As a result, the dependent variable "Remedy Effectiveness" was developed with all possible combinations of "before" and "after" SDL behaviors. The logic driving the development of the scale assumes the viewpoint of a retailer, for whom the substitute behavior is more desirable than the delay behavior which, in turn, is more desirable than the leave behavior. Thus, for instance, a remedy that changes a "before" behavior of leave into an "after" behavior of substitute is more effective than a remedy that accomplishes no change in behavior. The Remedy Effectiveness scale is presented in Table 4 below. The higher the score, the more effective the remedy.

\section{Results}

In this section it was present the results for each of the 5 remedies considered in the research. In each case, it was first present the overall result of the remedy on leave behavior. The overall result excludes cases where the initial response was to substitute the item, since

Table 4. Remedy effectiveness scale.

\begin{tabular}{|c|c|c|c|}
\hline \multirow{2}{*}{ Scale } & \multicolumn{2}{|c|}{ SDL behavior } & \multirow{2}{*}{$\begin{array}{l}\text { Change of } \\
\text { behavior }\end{array}$} \\
\hline & Before & After & \\
\hline 1 & Substitute & Leave & Most Negative \\
\hline 2 & Delay & Leave & Negative \\
\hline \multirow[t]{2}{*}{3} & Substitute & Delay & Slightly Negative \\
\hline & Leave & Leave & \\
\hline \multirow[t]{2}{*}{4} & Delay & Delay & Neutral \\
\hline & Substitute & Substitute & \\
\hline 5 & Leave & Delay & Slightly Positive \\
\hline 6 & Delay & Substitute & Positive \\
\hline 7 & Leave & Substitute & Most Positive \\
\hline
\end{tabular}

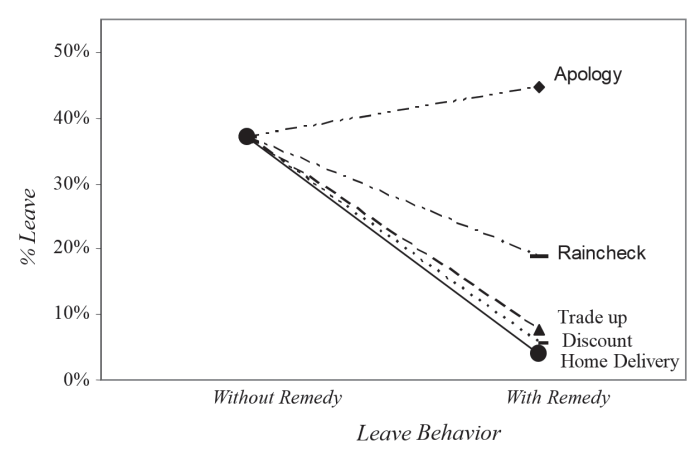

Figure 3. Overall impact of five remedies on leave behavior. it is unlikely that a remedy would be offered in that case. It was then presented the ANOVA results with the main and two-way interaction effects obtained when the consumer characteristics and shopping situation variables were considered. The overall result for the five remedies is presented in Figure 3.

\subsection{Apology}

Note, in Figure 3, that the impact of an apology on leave behavior might be counterproductive. Following the apology, the percentage of consumers leaving the store in response to a stockout rose from $37 \%$ to $44.6 \%$. This may be explained by the apology statement in the experiment that explicitly states that, other than apologizing, there is nothing that the store can do for the consumer to remedy the stockout.

The only significant main effect is urgency. As displayed in Table 5, an apology is even less effective as a remedy if the consumer's urgency of purchase is high. This main effect is qualified by one of the three significant interactions in Table 5. An apology is more effective as a remedy when brand loyalty is low and the purchase is planned. However, an apology is less effective as a remedy when high brand loyalty is combined with urgency and when the consumer is both brand loyal and store loyal.

While apparently counterintuitive, the result that apology is less effective as a remedy when the consumer is both brand loyal and store loyal can be explained as a violation of the consumer's expectation. The consumer sees himself or herself as a loyal store customer who expects his or her preferred brand to be in stock. When this expectation is violated, and all that the consumer gets from the store is an apology and no further action, the likelihood increases that the consumer will leave the store.

\subsection{Raincheck}

The overall impact of a raincheck on the percentage of consumers who leave the store in response to a stockout is moderately strong. Figure 3 shows that the percentage of consumers leaving the store in response to a stockout declined from $37 \%$ to $18.8 \%$. As in the case of apology, the only significant main effect on the effectiveness of a raincheck is urgency. Table 6 shows that the relationship is negative. The raincheck is less effective when urgency is high.

\subsection{Home delivery}

Figure 3 suggests that home delivery is overall the most effective remedy. The percentage of consumers who leave the store after experiencing a stockout is 
Table 5. ANOVA results - apology.

\begin{tabular}{lccccc}
\hline \multicolumn{1}{c}{ Term } & Effect & Coef & SE Coef & $\mathrm{t}$ & $\mathrm{p}$ \\
\hline Urgency & -0.3590 & -0.1795 & 0.0656 & -2.74 & 0.006 \\
Pre-Visit Agenda*Brand Loyalty & 0.3575 & 0.1788 & 0.0638 & 2.80 & 0.005 \\
Urgency*Brand Loyalty & -0.2516 & -0.1258 & 0.0642 & -1.96 & 0.051 \\
Brand Loyalty*Store Loyalty & -0.3172 & -0.1586 & 0.0684 & -2.32 & 0.021 \\
\hline
\end{tabular}

$\mathrm{S}=1.4179 \mathrm{R}-\mathrm{Sq}=0.0828 \mathrm{R}-\mathrm{Sq}(\mathrm{adj})=0.0337$.

Table 6. ANOVA results - raincheck.

\begin{tabular}{cccccc}
\hline Term & Effect & Coef & SE Coef & t & $p$ \\
\hline Urgency & -0.1860 & -0.0930 & 0.0189 & -4.93 & 0.000 \\
\hline$S=0.3773$ R-Sq= 0.0909 R-Sq(adj)= 0.0423. & & & & &
\end{tabular}

Table 7. ANOVA results - home delivery.

\begin{tabular}{lccccc}
\hline \multicolumn{1}{c}{ Term } & Effect & Coef & SE Coef & $\mathrm{t}$ & $\mathrm{p}$ \\
\hline Urgency & -1.1504 & -0.5752 & 0.0627 & -9.18 & 0.000 \\
Brand Loyalty & 0.2645 & 0.1323 & 0.0625 & 2.12 & 0.035 \\
Pre-Visit Agenda*Urgency & -0.2661 & -0.1331 & 0.0542 & -2.45 & 0.014 \\
\hline
\end{tabular}

$\mathrm{S}=1.2523 \mathrm{R}-\mathrm{Sq}=0.2322 \mathrm{R}-\mathrm{Sq}(\mathrm{adj})=0.1911$.

Table 8. ANOVA results - trade-up.

\begin{tabular}{|c|c|c|c|c|c|}
\hline Term & Effect & Coef & SE Coef & $\mathrm{t}$ & $p$ \\
\hline Urgency & -0.6020 & -0.3010 & 0.06606 & -4.56 & 0.000 \\
\hline Store Loyalty & -0.3102 & -0.1551 & 0.07156 & -2.17 & 0.031 \\
\hline
\end{tabular}

$S=1.3205 R-S q=0.1162 R-S q($ adj $)=0.0689$.

reduced from 37\% to only 4\%. Approximately 8 out of 9 consumers who were offered home delivery accepted it and switched their behavior away from leaving the store.

While the overall effectiveness of home delivery as a remedy is quite strong, there are two significant main effects and one significant interaction with the consumer characteristics and shopping situations that help qualify this effectiveness. As indicated in Table 7, the two main effects are urgency and brand loyalty. Urgency carries a negative sign. As expected, consumers are less likely to accept home delivery if there is urgency to purchase the product. The result for brand loyalty is also expected. It carries a positive sign. Brand loyal consumers are more likely to accept home delivery of their preferred brand.

The significant interaction is pre-visit agenda and urgency. It qualifies the main effect observed for urgency. Home delivery is most effective as a remedy whenever the purchase is by impulse in a non-urgent condition. The key issue to understand this effect is that after home delivery is offered as a remedy to the stockout, the rate of acceptance is usually very high. As noted above, few consumers leave the store after this remedy is offered. However, before the remedy is offered, there are differences in the percentage of consumers who leave the store after a stockout. Thus, home delivery is most effective as a remedy under the condition where the percentage of consumers leaving the store before the remedy is offered is highest. This is because there is more room for improvement to reduce the number of consumers leaving the store.

\subsection{Trade-up}

Trade-up is an effective remedy to reduce the percentage of consumers leaving the store as a result of experiencing a stockout. In our sample, the percentage was reduced from $37 \%$ to $7.8 \%$. In other words, approximately three out of four consumers offered a trade-up decided not to leave the store.

Table 8 suggests two main effects and no significant interactions among the consumer characteristics and shopping situations considered in the experiment. The two main effects are urgency and store loyalty. In both cases, the sign of the relationship is negative. This is a counterintuitive result because a positive relationship is expected. The more urgent the shopping situation, the more likely that the consumer would accept the trade-up offer. By the same token, the more store loyal the consumer, the more likely that the trade-up offered by the store would be accepted.

The reason for the negative sign is the same for both variables. It was explain the case of urgency first. Note, in Table 9, that in the "not urgent" condition, the number of consumers moving toward substitution as a result of being offered a trade-up is substantial. However, note also that in the "urgent" condition the number of consumers substituting the out-of-stock item is already quite high before 
Table 9. Consumer response to trade-up offer in urgent and not urgent conditions.

\begin{tabular}{cccc}
\hline & \multicolumn{2}{c}{ Trade-Up Offer } \\
\cline { 3 - 4 } & & Before & After \\
\hline \multirow{2}{*}{ Not Urgent } & Substitute & 83 & 229 \\
& Delay & 64 & 14 \\
& Leave & 129 & 33 \\
& Substitute & 195 & 265 \\
& Delay & 6 & 1 \\
& Leave & 75 & 10 \\
\hline
\end{tabular}

the trade-up is offered. This renders the remedy less effective because consumers were substituting already before being offered the trade-up. In this case, there is no change in behavior after the remedy is accepted. Thus the sign is negative because under the "urgent" condition there are many cases where the score in the remedy effectiveness scale remains unchanged and the resulting average score is lower than in the "not urgent" condition. In other words, a trade-up offer is less effective as a remedy when consumers are likely to trade-up anyway without the remedy.

The logic explaining the result for the store loyalty variable is the same. A high proportion of store loyal consumers would have responded to the stockout by substituting the item before the item was offered. Retailers should exercise caution when offering this remedy because they may offer it to consumers who would substitute the out-of-stock item even in the absence of the remedy.

\subsection{Discount}

Discount is an effective remedy. After being offered this remedy, the percentage of consumers leaving the store in response to a stockout was 5.6\%. This means that approximately five out of six consumers accepted the discount offer. This compares favorably with the remedies apology, raincheck and trade-up, but is less effective than home delivery.

Possibly because discount and trade-up are perceived similarly by consumers, the main effects and interactions uncovered for this remedy parallel those for the trade-up remedy. The directions of relationships were also the same, as are the suggested explanations for the results. It is therefore unnecessary to repeat them in this section.

\section{Conclusions, limitations and managerial implications}

Recall that the objective of the research is to investigate the effect of five remedies on consumer response to stockouts. The purpose of using remedies is to induce consumers to not leave a store in response to a stockout. It was considered the following five remedies: apology, raincheck, home delivery, trade-up and discount. In addition, it was researched the impact of four consumer characteristics and three shopping situations on the effectiveness of each remedy. The four consumer characteristics considered were brand loyalty, store loyalty, perceived store prices and perceived risk. The three shopping situations considered were urgency to purchase the item, pre-visit agenda and surprise with the stockout.

\subsection{Conclusions}

Remedies apparently work. With the exception of apology, all remedies considered in this research produced substantial reductions in the percentage of consumers intending to leave the store in response to a stockout. This reduction varied from 49 to 89 percent. A summary of the research results is in Table 10 .

The most effective remedy is home delivery. Trade-up and discount are very effective as well. The effectiveness of a raincheck is moderately strong. The least effective remedy is apology which, in fact, can be counterproductive and actually increase the percentage of consumers leaving the store in response to a stockout.

While this paper did not explicitly consider the cost of offering each remedy, there apparently isn't a strong relationship between the cost of a remedy and its effectiveness. A cost estimate of about 10 dollars is not unreasonable for home delivery. This is less expensive than the 50 dollar discount or the value of a trade-up considered in this research. Recall that trade-ups and discounts are less effective than home delivery in changing SDL behavior.

Of the consumer characteristics and shopping situations considered in the research, urgency is the most impactful. There is a main effect of urgency on all five remedies. The effect of urgency on three of the remedies, apology, raincheck and home delivery, is to render the remedy less effective. That is, the greater the urgency to purchase the item, the lower the effectiveness of these three remedies in changing SDL behavior.

The effect of urgency on the two other remedies, trade-up and discount, is more nuanced. If the remedy is offered only to consumers who would have left the store after experiencing a stockout, urgency increases the effectiveness of the remedy. On the other hand, if the trade-up or discount is offered to all consumers who experienced a stockout, the remedy will be in many instances ineffective because it is also offered to consumers who would have substituted the missing 
Table 10. Summary of findings.

\begin{tabular}{lccc}
\hline \multicolumn{1}{c}{ Remedy } & Overall Leave $\%$ & Main Effects & Interactions \\
\hline Apology & 44.6 & Urgency & Pre-Visit Agenda*Brand Loyalty Urgency*Brand Loyalty \\
Raincheck & 18.8 & Urgency & Loyalty Brand *Store Loyalty \\
Home Delivery & 4.0 & Urgency & Pre-Visit Agenda*Urgency \\
Trade-Up & 7.8 & Urgency & \\
Discount & 5.6 & Store Loyalty & \\
\hline
\end{tabular}

item even in the absence of the remedy. As a result, retailers should use caution when offering a trade-up or a discount as a remedy. When implementing the policy, it is important to consider the implications of also offering the remedy to consumers who would have substituted the missing item anyway. Doing so adds cost without adding revenue.

Another important variable is store loyalty. There is a main effect of store loyalty on the effectiveness of trade-up and discount as remedies to a stockout. As in the case of urgency, store loyalty increases the effectiveness of the remedy whenever either of them is offered to consumers who would have left the store in response to a stockout. When the trade-up or discount are offered to all consumers who experience a stockout, they are less effective because they are also offered to consumers who would have substituted the out-of-stock item even in the absence of a remedy.

Brand loyalty has a positive main effect on the effectiveness of home delivery. As expected, brand loyal consumers are more likely to accept a home delivery offer of their preferred brand. Overall, this paper conclude that home delivery is the most effective remedy, except when the consumer is experiencing an urgent shopping situation. In this case, trade-up or discount are the most effective.

\subsection{Limitations}

As in any research effort there are limitations to this study. First is that the cost of offering remedies was not considered explicitly. Second, it was made choices for the value of a trade-up and a discount. Replication with different values may yield different results. Third, the results may not replicate for a different product category. Recall that it was used TABLETs in this research. Fourth, while this paper has previously justified the use of a student sample, it was recognized that this is a limitation in this research. A student sample may be perceived as a limit to the external validity of the research, although it was having also shown that students are in fact actual users of TABLETs. Finally, results may vary in a different cultural setting.

\subsection{Managerial implications}

As noted earlier, prior research shows that in the past decades the rate of stockouts among retailers did not decline. It was also noted earlier that it is unlikely that stockouts can be $100 \%$ avoided. Therefore, it is reasonable to assume that a level of stockouts will always remain and that retailers will continue to deal with customers in the aftermath of stockouts. To implement remedies as tools to manage stockouts, it is important to understand the effect of remedies on stockout policy, the impact of remedies on the supply chain and the role of the supply chain on remedy delivery. It is additionally necessary to train store associates and measure SDL behavior.

Remedies impact stockout policy. This is a consequence of the effect of remedies on consumer behavior. If a remedy induces consumers to not leave the store in response to a stockout, the implications go beyond the avoided lost sales to impact stockout policy itself. If remedies are acceptable, then a level of stockouts may be acceptable as well. Thus, consumer response to remedies is an input to determine an acceptable level of stockouts that balances the cost of stockouts against the cost of carrying inventory. This impacts both the supply chain and the management of retail stores.

The supply chain has a role in avoiding and mitigating the effect of stockouts. Of particular importance are replenishment policy, the level and location of inventory and the cost of emergency shipments. The stockout rate may be reduced by replenishing stores more frequently. This, of course, must be balanced against the logistics costs of transportation, warehousing and information technology. Stockout rates may also be managed by keeping higher inventory levels and by placing inventory closer to stores. Finally, stockouts often increase the demand for emergency shipments as stores need unscheduled shipments to replenish out-of-stock inventory. The latter is increasingly a critical issue as transportation costs continue to rise. In cases where remedies are shown to be effective, they may play a role in reducing supply chain cost by helping determine an acceptable level of stockouts and by reducing the need for emergency shipments. 
The supply chain also has a role in the delivery of remedies. In particular, logistics managers are most likely the ones to be tasked with designing and implementing a process to home deliver out-of-stock items. The related cost and service issues are well known to logistics managers. Logistics managers would likely also handle the process if some of the items are later returned by customers. The implementation of rainchecks as a remedy also impacts the supply chain. There is a need to replenish the out-of-stock item. There are additional inventory management and sales forecasting implications if the consumer is able to cash the raincheck in a different store from where the stockout occurred. Finally, in the case of implementing coupon and trade-up as remedies, it is important to understand the cross-elasticity of demand among items because this would facilitate anticipating which items would be targeted by consumers once the remedy is offered. Clearly, this would also have an impact on inventory management and sales forecasting.

Retailers may benefit from training store associates. Whenever interaction with consumers present an opportunity, store associates may attempt to recognize the level of urgency of purchase and store loyalty exhibited by consumers. If empowered to do so, store associates would then use this information to select the right remedy. For example, if a consumer has urgency in the purchase, then a discount may be offered. Otherwise, home delivery may be a better choice.

Retailers also need to understand the SDL behavior of their customers. If a large share of customers substitute the missing item when encountering a stockout, then remedies such as trade-up or discount are not recommended. This is because the remedy would be offered to customers who would have substituted the item even in the absence of a remedy. Finally, firms should understand the cost and benefit of remedies. This is important to ensure that the cost of the remedy does not exceed the cost of the stockout.

In sum, the results in this research suggest that the percentage of customers who leave a store in response to a stockout can be substantially reduced by offering remedies to affected consumers. It was also suggest that different remedies lead to different results given the nature of the remedy itself, the characteristics of the consumer and the shopping situation. Thus, remedies are a tool managers may use to reduce the negative consequences of stockouts to retail stores and their supporting supply chains.

\section{References}

Aguiar, F. H. O., \& Sampaio, M. (2014). Identificação dos fatores que afetam a ruptura de estoque utilizando análise de agrupamentos. Produção, 24(1), 57-70. http://dx.doi. org/10.1590/S0103-65132013005000020.

Anderson, E. T., Fitzsimons, G. J., \& Simester, D. (2006). Measuring and mitigating the costs of stockouts. Management Science, 52(11), 1751-1763. http://dx.doi. org/10.1287/mnsc. 1060.0577.

Berger, R. (2003). ECR - Optimal Shelf Availability: increasing shopper satisfaction at the moment of truth. ECR Europe Publication. Retrieved in 26 May 2009, from http://ecr-all. org/wp-content/uploads/pub_2003_osa_blue_book.pdf.

Bhargava, H. K., Sun, D., \& Xu, S. H. (2006). Stockout compensation: joint inventory and price optimization in electronic retailing. INFORMS Journal on Computing, 18(2), 255-266. http://dx.doi.org/10.1287/ijoc.1040.0091.

Brickman, P. (1981). “ls it real?". In J. H. Harvey, W. lckes \& R. F. Kidd (Eds.), New directions in attribution research (Vol. 2, pp. 23). Hillsdale: Lawrence Erlbaum Associates.

Campo, K., Gijsbrechts, E., \& Nisol, P. (2000). Towards understanding consumer response to stockouts. Journal of Retailing, 76(2), 219-242. http://dx.doi.org/10.1016/ S0022-4359(00)00026-9.

Coca-Cola Retailing Research Councils. Andersen Consulting. (1996). Where to look for incremental sales gains: the retail problem of out-of-stock merchandise. Atlanta: The Coca-Cola Research Councils.

Corsten, D., \& Gruen, T. (2003). Desperately seeking shelf availability: an examination of the extent, the causes, and the efforts to address retail out-of-stocks. International Journal of Retail \& Distribution Management, 31(12), 605-617. http://dx.doi.org/10.1108/09590550310507731.

Corsten, D., \& Gruen, T. (2004). Stock-outs cause walkouts. Harvard Business Review, 85(2), 26-28.

Deck, C., \& Smith, V. (2013). Using Laboratory Experiments in Logistics and Supply Chain Research. Journal of Business Logistics, 34(1), 6-14. http://dx.doi.org/10.1111/jbl.12006.

Emmelhainz, L. W., Emmelhainz M. A., \& Stock, J. R. (1991). Logistics Implications of Retail Stockouts. Journal of Business Logistics, 12(2), 129-141.

Erdem, T., \& Swait, J. (1998). Brand equity as a signaling phenomenon. Journal of Consumer Psychology, 7(2), 131157. http://dx.doi.org/10.1207/s15327663jcp0702_02.

Fitzsimons, G. J. (2000). Consumer response to stockouts. The Journal of Consumer Research, 27(2), 249-266. http:// dx.doi.org/10.1086/314323.

Grocer, P. (1968). The stockout study: a crusade against stockouts (pp. S1-S31). New York: The National Association of Food Chains. Retrieved in 26 May 2009, from https://www4. infotrieve.com/neworders/Order_Cart.asp

Gruen, T. W., Corsten, D. S., \& Bharadwaj, S. (2002). Retail outof-stocks: a worldwide examination of extent, causes and consumer responses. Washington: Grocery Manufacturers of America.

Kim, M., \& Lennon, S. J. (2011). Consumer response to online apparel stockouts. Psychology and Marketing, 28(2), 115144. http://dx.doi.org/10.1002/mar.20383.

Peckham, J. O. (1963). The consumer speaks. Journal of Marketing, 27(4), 21. http://dx.doi.org/10.2307/1248641. 
Petty, R. E., \& Cacioppo, J. T. (1996). Addressing disturbing and disturbed consumer behavior: ls it necessary to change the way we conduct behavioral science? JMR, Journal of Marketing Research, 33(1), 1-8. http://dx.doi. $\operatorname{org} / 10.2307 / 3152008$.

Schary, P. B., \& Christopher, M. (1979). The anatomy of a stock-out. Journal of Retailing, 55(2), 59-70.

Sloot, L. M., Verhoef, P. C., \& Franses, P. H. (2005). The impact of brand equity and the hedonic level of products on consumer stock-out reactions. Journal of Retailing, 81(1), 15-34. http://dx.doi.org/10.1016/j.jretai.2005.01.001.

Vasconcellos, L. H. R., \& Sampaio, M. (2009). The stockouts study: an examination of the extent and the causes in the
São Paulo supermarket sector. BAR - Brazilian Administration Review, 6(3), 263-279.

Verbeke, W., Farris, P., \& Thurik, R. (1998). Consumer response to the preferred brand out-of-stock situation. European Journal of Marketing, 32(11/12), 1008-1028. http://dx.doi. org/10.1108/03090569810243640.

Walter, C. K., \& Grabner, J. R. (1975). Stockout models: empirical tests in a retail situation. Journal of Marketing, 39(3), 56-60. http://dx.doi.org/10.2307/1250902.

Zinn, W., \& Liu, P. C. (2001). Consumer response to retail stockouts. Journal of Business Logistics, 22(1), 49-71. http://dx.doi.org/10.1002/j.2158-1592.2001.tb00159.x. 